\title{
A RESPONSABILIDADE PELA SAÚdE
}

Sueli Gandolfi Dallari

Diretora-Geral do Centro de Estudos e Pesquisas de Direito Sanitário da USP

\begin{abstract}
Resumo: Após rápido exame da evolução semântica do termo responsabilidade e da amplitude de compreensão do termo saúde, para fixação das barreiras postas à definição da responsabilidade pela saúde, são examinadas algumas situações determinadas: a responsabilidade pela saúde na ordem internacional, a responsabilidade constitucional pela saúde, a responsabilidade pela saúde objeto da ação estatal e a responsabilidade civil e penal por produtos e serviços de saúde. Conclui-se pela necessidade da exata determinação das variáveis que permitam a fixação da responsabilidade pela saúde como exigência constitucional no Estado Democrático de Direito.
\end{abstract}

Resumé: Après l'examen de l'evolution sémantique du terme responsabilité et de l'amplitude de compréhension du terme santé, pour fixer les barrières mises à l'engagement de la responsabilité pour la santé, quelques situations precises sont examinées: la responsabilité constitutionelle pour la santé, la responsabilité pour la santé soumise à l'action étatique et la responsabilité civile et pénale pour les produits et les services de santé. La conclusion met en évidence la necessaire délimitation exacte des variables pour l'entraînement de la responsabilité pour la santé, exigence constitutionnelle de l'État démocratique de droit.

Unitermos: Responsabilidade; Teoria geral do direito; Direito público e direito sanitário.

\section{RESPONSABILIDADE: TEXTO E CONTEXTO}

Sem dúvida o termo responsabilidade é polissêmico. Essencialmente derivado da história dos povos que lhe foram acrescentando novos sentidos ele é mesmo desconhecido para alguns deles. É o caso dos gregos, onde ANADOKÉ ou UPENTHINON designam, especificamente, a caução (obrigação do devedor secundário) e a responsabilidade constitucional dos governantes frente ao juízes (reservado, portanto, ao direito público) $^{(1)}$.

(1) cf. VILLERS, R. Responsabilité pénale et responsabilité civele dans les droits helléniques in BOULET-SAUTEL, $M$. et al. La responsabilité à travers les ages. Paris, Economica, 1989 pág. 47. 
O direito romano é a fonte por excelência do significado jurídico dos nomes, para os Estados que nele basearam seu arcabouço jurisdicional. Todavia, ainda que se procure os precedentes antigos da responsabilidade nos direitos cuneiformes que não a conceituaram, apenas praticaram-na, observa-se "uma aspiração conforme ao sentido mais elementar de justiça; separar a pena da reparação"(2).

Nas línguas européias o termo responsabilidade aparece apenas no século XVIII mas tem, sem dúvida, raízes no direito romano: RESPONDERE. A sponsio, instituição muito importante no direito romano arcaico, previa a figura do devedor-SPONSOR, aquele que ao responder afirmativamente se obrigava a uma prestação. Previa, também, o RESPONSOR que se obrigava a responder pela dívida principal do outro. Assim, responder sempre implicou a idéia de ser o garantidor de eventos futuros. Em português o termo responsabilidade aparece pela primeira vez num texto, por derivação do francês "responsable", em $1813^{(3)}$. No francês "responsabilité" foi empregada pela primeira vez na lição de Necker: "A confiança nesse papel nasce da responsabilidade do governo", significado que o Estado acrescia a garantia de um título ${ }^{(4)}$.

A conclusão inicial fundada no exame da etimologia é que originariamente não se cogitava de falta quando se tratava de responsabilidade. Com efeito, nos exemplos do professor VILLEY, não se presupõe qualquer falta nem do pai que responde pelo casamento de sua filha, nem do devedor romano que deve "responder" a seus credores. A falta não era cogitada nem mesmo quando o móvel era a reparação dos danos, onde o direito romano abeberou-se da lição de Aristóteles. A verdadeira causa essencial da obrigação (contratual civil ou penal) era sempre a desordem instalada numa relação entre pessoas, o que se evidenciava, claramente, no reconhecimento de múltiplos casos de responsabilidade sem falta.

O racionalismo trouxe para o mundo laico, dessacralizando-o, o princípio da lei moral, o agir humano. A intenção subjetiva é que passou a tornar o homem responsável, não mais perante o tribunal divino, mas frente à humanidade, à sociedade, ao futuro. $\mathrm{O}$ direito descobriu o individualismo, passando a basear-se não mais na idéia de justiça (SUUM CUIQUE TRIBUIRE, AEQUABILITAS) objetiva, manutenção de determinada ordem, mas na noção das liberdades individuais, cuja defesa exigia o governo legislativo das ações humanas.

(2) cf. CARDASA A, G. Réparation et peine dans les droits cunéiformes et le droit romain in BOULET-SAUTEL, M. et al. op. cit., pág. 42.

(3) E E que ensina Antonio Geraldo da Cunha no Dicionário Etimológico.

(4) É o que informa HENRIOT, J. na note sur la date et le sens du mot "responsabilité" in Archives de philosophie du droit, 1977, pág. 60. 
E a responsabilidade, compreendida no campo moral, substituiu, para os positivistas, a justiça como fundamento da ordem jurídica ${ }^{(5)}$.

\section{SAÚdE: UM FENÔMENO INDIVIDUAL, COLETIVO E Sócio- CULTURAL}

O termo saúde apresenta grande imprecisão na linguagem natural. É a amplitude de compreensão que torna difícil, mesmo na linguagem técnica, sua delimitação. De fato, muito já se escreveu a respeito da conceituação da saúde durante a história da humanidade. Hipócrates, filósofo grego que viveu no século $\mathrm{V}$ a.C., refere a influência da cidade e do tipo de vida de seus habitantes sobre a saúde e afirma que o médico não cometerá erros ao tratar as doenças de determinada localidade quando tiver compreendido adequadamente tais influên$\operatorname{cias}^{(6)}$. Do mesmo modo, Paracelso, médico e alquimista suíço-alemão que viveu durante a primeira metade do século XVI, salientou a importância do mundo exterior (leis físicas da natureza e fenômenos biológicos) para a compreensão do organismo humano. Devido a sua experiência como mineiro pôde mostrar a relação de certas doenças com o ambiente de trabalho ${ }^{(7)}$. Também Engels, filósofo alemão do século XIX, estudando as condições de vida đe trabalhadores na Inglaterra, nos albores da Revolução Industrial, concluiu que a cidade, o tipo de vida de seus habitantes, seus ambientes de trabalho, são responsáveis pelo nível de saúde das populaçōes ${ }^{(8)}$.

Outra corrente de pensamento, entretanto, evoluiu no sentido de conceituar a saúde como sendo a ausência de doenças. Pode-se encontrar a origem de tal corrente nos trabalhos do filósofo francês do início do século XVII, Des$\operatorname{cartes}^{(9)}$, que ao identificar o corpo humano à máquina acreditou poder descobrir a "causa da conservação da saúde". Nessa linha de evolução, o século XIX enfatizou o caráter mecanicista da doença. Sob o predomínio da máquina, a sociedade industrial procurou explicar a doença como sendo o defeito na linha de montagem que exigia reparo especializado. Exatamente nesse momento

(5) CF VILLEY, M. Esquisse historique sur le mot responsable in BOULETSAUTEL, M. et al. op. cit., pág. 85.

(6) cf. HIPPOCRATES. The medical works of hippocrates; a new translation from the original greek made especially for English readers by the collaboration of John Chad wick and W. N. Mann. Springfield, I11. Thomas, 1950, pág. 90-111.

(7) cf. PARACELSUS. On miner's sickness and other miner's diseases. In: PARACELSUS. Four teratises of theuphrastus von Hohenheim called PARACELSUS. Baltimore, Johns Hopkins Press, 1941, pág. 43-1 26.

(8) cf. ENGELS, F. A situação da classe trabalhadora na Inglaterra. Sāo Paulo, G lobal Ed., 1986.

(9) cf. DESCARTES, R. Discurso sobre o método. Rio de Janeiro, Simōes, 1952. 
os trabalhos de Pasteur ${ }^{(10)}$ e Koch ${ }^{(11)}$ provam a teoria sobre a etıologia específica das doenças e fornecem, então, a causa que explica o defeito na linha de montagem humana.

O ambiente social do fim do século passado e primeira metade do século $\mathrm{XX}$, auge da Revolução Industrial, propiciou o debate entre as duas grandes correntes que buscaram conceituar a saúde. De um lado, grupos marginais ao processo de produção que viviam em condiçōes de vida miseráveis, enfatizavam a compreensão da saúde como diretamente dependente de variáveis relacionadas ao meio ambiente, ao trabalho, à alimentação e à moradia. A incidência de tuberculose, por exemplo, era acentuadamente mais elevada nas camadas sociais com menos renda. Por outro lado, a descoberta dos germes causadores de doença e seu subseqüente isolamento, que possibilitou o desenvolvimento de remédios específicos, falava a favor da conceituação da saúde como ausência de doenças. Com efeito, as drogas aperfeiçoadas, adequadamente empregadas, resultaram na cura de várias doenças, salvando muitas vidas.

A intervenção de fatores políticos foi, contudo, aparentemente o marco final de tal debate. A experiência de uma Grande Guerra apenas 20 anos após a anterior, provocada pelas mesmas causas que haviam originado a predecessora e, especialmente, com capacidade de destruição várias vezes multiplicada, forjou um consenso. Carente de recursos econômicos, destruída sua crença na forma de organização social, alijada de seus líderes, a sociedade que sobreviveu a 1944 sentiu a necessidade ineludível de promover um novo pacto. Tal pacto, personificado na Organização das Naçōes Unidas, fomentou a Declaração Universal dos Direitos do Homem, ao mesmo tempo em que incentivou a criação de órgãos especiais dedicados a garantir alguns desses direitos considerados essenciais aos homens. A saúde, reconhecida como direito humano, passou a ser objeto da Organização Mundial de Saúde (OMS) que, no preâmbulo de sua Constituição (1946), assim a conceitua: "Saúde é o completo bem-estar físico, mental e social e não apenas a ausência de doença"(12). Observa-se, então, o reconhecimento da essencialidade do equilibrio interno e do homem com o ambiente (bem-estar físico, mental e social) para a conceituação da saúde, recuperando os trabalhos de Hipócrates, Paracelso e Engels.

(10) cf. PASTEUR, L. Etudes sur la bière. Paris, Gautiher-Villars, 1876.

(11) cf. KOCH, R. Die Aetiologie und die Bekanmfung der Tuberkulose. Leipzig, Verlag von Johann Ambrosius Barth, 1912.

12) A Constituição adotada pela Conferência Internacional da Saúde, realizada em New Y ork de 19 a 22 de julho de 1946 e assinada em 26 de julho de 1946 por representantes de 61 (sessenta e um) Estados, apresenta esta definição como o primeiro princípio básico para a "felicidade, as relaçōes harmoniosas e a segurança de todos os povos" 
A saúde, assim conceituada, sempre foi objeto de atenção tanto individual como coletiva. Testemunha da atenção individual são as regras técnicas e deontológicas estabelecidas pelo mesmo Hipócrates quando trata do relacionamento do médico com o paciente ${ }^{(13)}$. Não se restringe, entretanto, à antigüidade $o$ aspecto individual da atenção à saúde que se revela no mundo contemporâneo, por exemplo, na referência ao contrato existente entre o médico e o doente. Por outro lado os hospitais, da Idade Média aos tempos modernos, revelam o aspecto comunitário da medicina.

Atualmente, portanto, a saúde não tem apenas um aspecto individual que respeita somente à pessoa. Ao contrário, o aspecto coletivo freqüentemente sobrepuja o individual, seja porque a eficácia da prevenção depende do recurso ao poder do Estado que, em nome da igualdade entre o povo, obriga a certos comportamentos (vacinação, por exemplo), seja porque os custos da proteção são muito elevados.

É, no entanto, a enorme amplitude do termo saúde que sobreleva o aspecto sócio-econômico-cultural envolvido em sua conceituação. Com efeito, não basta a existência de serviços destinados à promoção, proteção e recuperação sanitária adequados e em números suficientes, nem a existência de normas legais prevendo todas as hipóteses de agravos à saúde pública, se o Estado não tiver atingido um nível tal de desenvolvimento sócio-econômico e cultural que lhe permita dispor de todos os recursos técnicos existentes, atender a todas as necessidades de infra-estrutura e possuir uma população educada para a saúde. Assim, o Estado subdesenvolvido que não possui todos os recursos técnicos conhecidos para o tratamento de certas patologias, que não dispõe de meios econômicos para promover o saneamento ambiental ou que não educou sua população para a saúde, não pode atingir o mesmo nível sanitário daquele desenvolvido que já emprega tais recursos sócio-econômicos e culturais.

\section{A RESPONSABILIDADE PELA SAÚDE}

Delimitada a área de abrangência de cada termo, fixam-se as barreiras postas à definição da responsabilidade pela saúde. Tema básico na contemporaneidade porque fundamento da ordem jurídica que deve garantir a saúde como direito.

A busca da compreensão do conceito de responsabilidade pela saúde exige que se examine, atentamente, várias situações determinadas. Interessa inicialmente conhecer o papel do Estado, analisando tanto os aspectos individuais quanto coletivos da saúde e sua responsabilização pelo indivíduo e pelo próprio Estado. Mas interessa também, especialmente quando se considera a variável sócio-econômico-cultural na conceituação de saúde, conhecer-se a responsabilização internacional entre os Estados.

(13) HIPPOCRATE, La consultation, Paris, Hermann, 1986. 


\section{a. A responsabilidade pela saúde na ordem internacional}

O direito internacional por suas características especiais está sempre muito próximo do direito das gentes, onde o costume exerce papel primordial. A noção de responsabilidade vem tentando se desvencilhar da idéia do pecado que lhe foi introduzida na Idade Média Cristã. Assim, o debate que nos anos 30 do século XX cindiu os doutrinadores entre partidários e adversários da responsabilidade por risco, apenas nos anos 70 ganha os foros internacionais. E é curioso que nesse momento tal debate já estava superado nas jurisprudências internas, condenando o regime jurídico da responsabilidade objetiva a um uso restrito. Por outro lado, a tendência à objetivação da reparação tem tido espetacular difusão e sucesso nos tempos hodiernos, talvez porque a teoria formaI seja pouco apropriada à realidade sócio-econômica.

Sem dúvida, tanto os problemas ecológicos originários do desenvolvimento tecnológico e industrial, quanto os ligados especificamente às epidemias contemporâneas e aos seus remédios requerem a determinação da responsabilidade internacional. Ora, a positivação da responsabilidade objetiva é derrogatória e se inscreve necessariamente na conclusão de acordos especiais que exigem o conhecimento preciso tanto dos aspectos jurídicos quanto sanitários envolvidos. Assim como tal conhecimento é imprescindível à determinação técnica da expressão monetária dos padrões de "diligência devida", meio para a padronização da responsabilidade internacional por fato ilícito.

É inegável que a noção de fato ilícito perdeu subjetividade porque foi suplantada pela objetivação da reparação, decorrente do empirismo do economista $^{(14)}$. Urge, portanto, sistematizar o conhecimento dos campos envolvidos para se conseguir efetiva proteção jurídica à saúde, especialmente no que respeita à sociedade internacional.

\section{b. A responsabilidade constitucional pela saúde}

O Estado moderno nasceu politicamente responsável. Após discorrer sobre as razões que tornam conveniente a transferência de direitos do homem para o soberano, Hobbes afirma que nada é capaz de reforçar qualquer pacto de paz senão o medo das conseqüências de faltar à palavra dada ${ }^{(15)}$. E Locke, suavizando o diagnóstico radical de seu predecessor contemporâneo, assim declara a finalidade do pacto social: "E por este modo os homens deixam o estado de natureza para entrarem no de comunidade, estabelecendo um juiz na terra, com autoridade para resolver todas as controvérsias e reparar os danos que atinjam

(14) cf. DUPUY, P. La responsabilitê internationale des états pour les domages d'origine technologiche et industrielle. Paris, Pedone, 1976, pág. 258.

(15) cf. HOBBES, T. Leviatã, especialmente nos capítulos XIV e XV da primeira parte. 
qualquer membro da comunidade; juiz esse que é o legislativo ou os magistrados por ele nomeados"(16).

Foi Rousseau, porém, aquele que, ao ditar as bases do Estado liberal-burguês, proporcionou a expansão do termo responsabilidade. Quanto ao Estado, pessoa pública com uma única vontade: "a comum conservação (dos homens) e o bem-estar geral" (17), ela aparece como um corolário dos direitos do homem, especialmente do princípio da igualdade face aos encargos públicos, declarados em 1789.

Para que a vontade geral, posta na Constituição, seja a única fonte de constrangimentos para os homens e permita o alcance do bem-estar geral, os constitucionalistas da segunda metade do século XX desenvolveram teorias sobre o papel dirigente da Constituição e da vinculação do legislador pela decorrente. Ora, a abrangência do termo saúde faz com que freqüentemente sua garantia envolva o conflito entre direitos fundamentais e defesa de outros interesses constitucionalmente protegidos, obrigando, portanto, o legislador a ponderar, considerando os vários resultados jurídicos e a necessidade de otimização dos fins constitucionais ${ }^{(18)}$. E, sem dúvida, é tal ponderação concreta que permitirá verificar da prossecução da saúde, fim constitucionalmente previsto, permitindo a responsabilização jurídico-política do Estado.

\section{c. A responsabilidade pela saúde objeto da ação estatal}

Porque os Estados contemporâneos são repúblicas (res publica) é o Direito que os dirige, isto é, todos os órgãos de governo e todos os cidadãos estão sob a ordem jurídica e são, portanto, igualmente responsáveis. Partindo desse pressuposto Soto Kloss trata da responsabilidade do Estado sob a ética da vítima, insistindo que é "a situação dela que deve ser analisada como dado primário, e sua posição jurídica frente ao Estado autor do dano"(19).

Revela-se, então, o desconforto que vem atingindo os doutrinadores da responsabilidade jurídica objetiva. Com efeito, a generalização da teoria do ris-

(16) cf. LOCKE, J. Segundo tratado sobre o governo. São Paulo, Ibrasa, 1963, pág. 55.

(17) cf. ROUSSEAU, J.J. O Contrato social e outros escritos. Sāo Paulo, Cultrix, 1971, pág. 103.

(18) Nesse sentido é importante a sistematização feita por José Joaquim Gomes Canobilho em sua tese "Constituição dirigente e vinculação do legislador" (Coimbra, Coimbra, 1982 ).

(19) cf. SOTO KLOSS, E. La responsabilidad publica: enfoque politico in BANDEIRA DE MELLO, C.A. et al. Responsabilidad del Estado. Tucuman, UNSTA, 1982, pág. 40. 
co provocando indenizações, às vezes astronômicas, fixadas sem qualquer consideração subjetiva, seja do agente, seja da vítima, gerou conclusões que, dialeticamente, privilegiam o papel do juiz. Assim, "não é automático que existindo um dano, decorrente da atividade do Estado, sempre se tenha que indenizar, de modo integral ou total, pois existem nuanças que vem adequando aquele princípio à realidade. É a vítima quem determina (porque é ela o centro do sistema, pois responsabilidade implica reparação e a reparação é dada e condicionada pelo dano sofrido pela vítima) se o dano deve ser reparado, se será reparado, mas não integralmente pelo Estado", na lição do administrativista chileno. Também se advoga a distinção entre o comportamento lesivo omissivo e comissivo, prevendo-se a responsabilidade objetiva apenas no último caso ${ }^{(20)}$

A amplitude do campo de atuação da responsabilidade do Estado implica ainda consideraçōes sobre o dano que o servidor público, no exercício de suas funções, pode causar à própria administração por inobservância do dever de ofício. Ora, a leitura superficial desses temas revela a obviedade de sua importância no que refere a saúde, serviço público por natureza ${ }^{(21)}$

\section{d. A responsabilidade civil e penal por produtos e serviços de saúde}

O século das luzes generalizou a moralidade da responsabilidade. Especialmente no que concerne ao Direito Penal, só é imputável, e portanto passível de pena, aquele que agir conscientemente. É, contudo, no âmbito civil que se acentua o caráter moral da responsabilidade (de duvidosa moralidade, porém, haja vista que a rigorosa obediência às regras, obrigando apenas ao cumprimento do contrato, pode desculpar o desinteresse pela situação do próximo que não decorre diretamente de fato meu), apanágio do liberalismo. É necessário acentuar-se, também no que respeita à esses tipos de responsabilidade, a ineficácia da teoria para fundamentar decisões que estabéleçam a justiça ${ }^{(22)}$. O Direito, ou melhor, muitos juristas contemporâneos buscam a solução para o problema considerando os diversos fatores em causa.

Faz-se mister, em conseqüência, o tratamento bastante minucioso de cada situação, desenvolvendo-se, por exemplo, uma teoria para explicar a responsabilidade pelo produto e outra para esclarecê-la enquanto relacionada à presta-

(20) É esta a liçāo de Celso Antonio Bandeira de Mello na obra "Responsabilidad del Estado", já citada.

(21) Tomado como exemplo por entre outros, Bandeira de Mello, C.A. in Prestação de serviços públicos e administração indireta. São Paulo, Revista dos Tribunais, 1975, pág. 22. MEIRELLES, H.L. Direito administrativo brasileiro. São Paulo, Revista dos Tribunais, 1984, pág. 273.

(22) É a conclusão do professor VILLEY, na obra citada. 
ção de serviços. Mas, sobre tal divisão cumpre acrescentar várias outras que, tomando por modelo a prestação de serviços distinguem aqueles realizados por profissional "intelectual" dos demais. Ou, considerando apenas os produtos cujo uso possa afetar a saúde, separam os medicamentos dos cosméticos e dos pesticidas e esses dos alimentos.

A complexidade de todo o sistema de responsabilidade, que para ser justo necessita fornecer ao juiz critérios múltiplos para valoração dos fatores envolvidos na causa, pode ser ilustrada pelo exame da responsabilidade do pessoal médico ${ }^{(23)}$. Nesse caso, pode estar em causa, no âmbito da responsabilidade, a distinção entre trabalho intelectual e técnico a caracterizar a responsabilidade civil ou penal pela prestação de serviço. Mas também a responsabilidade administrativa decorrente seja de omissão, seja de ação de funcionário ou de servidor público, pode estar caracterizada.

\section{RESPONSABILIZAÇÃO PELA SAÚDE: EXIGÊNCIA DO ESTADO DE DIREITO}

O Estado Democrático de Direito, da Constituição brasileira, ou o Estado de Direito Democrático, da Constituição portuguesa, ou o Estado Social e 1 /emocrático de Direito, da onstituição espanhola ${ }^{(24)}$, se caracteriza pela vinculação dos poderes públicos, incorporando também obrigações que requeiram prestações positivas para garantia dos direitos sociais.

É de difícil compreensão o fato de que o campo mais importante de vinculação constitucional dos poderes públicos se refira à proibição do uso da força refletida no direito punitivo, penal ou de polícia administrativa. Assim, no Estado de Direito Liberal, cujas regras garantem os direitos fundamentais dos cidadãos impondo limitações aos seus poderes, geralmente a fixação de normas violando aquelas é causa de inexistência de tais normas. Por outro lado, o enunciado constitucional dos direitos a prestações estatais positivas não foi acompanhado de garantia social (técnica de defesa e justificação) adequada à sua tutela. Bem ao contrário o aterrador quadro pintado por Bobbio evidencia que a multiplicação das funções públicas na área econômica e social freqüentemente foi realizada às custas dos, por ele denominados, subgoverno; cripto

(23) Apenas a título exemplificativo veja-se: PAISIO, F. Responsabilité giuridica del personale delle Unitá Sanitarie locali, Parma, Casanova, 1982; GRAD, F. Public health law manual, Washington, American Public Health Association, 1970; e LEMAIRE, J. et IMBERT,J La responsabilité médicale. Paris, Presses Universitaires de France, 1985.

(24) Veja-se a respeito o alentado estudo do professor José Afonso da S ilva em seu Curso de Direito Constitucional Positivo. São Paulo, Revista dos Tribunais, 1989, pág. 99-108. 
governo e poder onividente ${ }^{(25)}$. Ou seja, na brilhante lição de FERRAJOLI, "não foi, enfim, nem teorizado nem realizado um estado social de direito, isto é caracterizado - em lugar de concessốes - por obrigações taxativamente estabelecidas e sancionadas, por direitos claramente definidos e acionáveis no confronto de órgãos públicos exatamente individualizados, e portanto, pela certeza, pela legalidade e pela igualdade na satisfação das expectativas"(26)

A delimitação da responsabilidade pela saúde, publicizando finalmente o poder no Estado Democrático de Direito, é função inderrogável do Poder Judiciário brasileiro, sob pena de ação inconstitucional.

São Paulo, março de $\Theta 90$.

(25) cf. BOBBIO, N. A democracia e o poder invisível in $\mathbf{O}$ futuro da Democracia. Rio de Janeiro, Paz e Terra, 1986, pág. 83-1 06.

(26) cf. FERRAJOLI, L. Diritto e Ragione: teoria del garantismo penale. Roma, Laterza, 1989, pág. 904. 